\title{
ATMOSPHERIC RADIOCARBON WORKSHOP REPORT
}

\author{
Jocelyn Turnbull ${ }^{1,2} \cdot$ Heather Graven ${ }^{3} \cdot$ John Miller $^{2,4} \cdot$ Scott Lehman $^{5} \cdot$ Workshop Participants
}

ABSTRACT. A workshop on atmospheric radiocarbon measurements was held in conjunction with the 21 st International Radiocarbon conference in July 2012. The main topics were intercomparison of measurements of ${ }^{14} \mathrm{C}_{\text {in }}$ atmospheric $\mathrm{CO}_{2}$, the potential for use of gas standards for atmospheric ${ }^{14} \mathrm{C}$ measurements, reporting of uncertainties, and expansion of intercomparison activities to other atmospheric trace gases. This report documents the discussions and conclusions of this workshop.

\section{INTRODUCTION}

Measurements of radiocarbon in atmospheric trace gases are becoming more widely used for a variety of scientific applications. There is, in particular, a growing focus on the use of the ${ }^{14} \mathrm{C}$ content of carbon dioxide $\left({ }^{14} \mathrm{CO}_{2}\right)$ as a tracer for fossil-fuel $\mathrm{CO}_{2}$ emissions, which requires high-precision measurement and comparability, as the ${ }^{14} \mathrm{C}$ measurement precision is often close to the size of the atmospheric signals of interest. Both the ${ }^{14} \mathrm{C}$ and atmospheric trace gas measurement communities have long histories of intercomparison activities to ultimately allow measurements from different laboratories to be used as a single data set. The World Meteorological Organization (WMO) holds a biannual meeting on Greenhouse Gas Measurement Techniques (GGMT), and publishes biannual Expert Group Recommendations for measurement, reporting, and intercomparison of greenhouse gases and related tracers (WMO 2011). ${ }^{14} \mathrm{C}$ in atmospheric trace gases has been included in these recommendations since 2005 . Only a small subset of the atmospheric ${ }^{14} \mathrm{C}$ community attended the 2011 GGMT meeting in Wellington, New Zealand, and a more detailed discussion was felt to be necessary. Therefore, a workshop on atmospheric ${ }^{14} \mathrm{C}$ measurements was convened as part of the 21 st International Radiocarbon Conference. This report documents the discussion and recommendations from the workshop, which will also be included in the next WMO/GGMT recommendations due to be published in 2013 .

The major topics of discussion were ongoing and new intercomparison activities for ${ }^{14} \mathrm{CO}_{2}$ measurements, the use of gas standards for accelerator mass spectrometry (AMS) ${ }^{14} \mathrm{CO}_{2}$ measurements, reporting of uncertainties for atmospheric ${ }^{14} \mathrm{C}$ measurements, and the need for intercomparison activities for ${ }^{14} \mathrm{C}$ in other atmospheric trace gases.

\section{INTERCOMPARISON ACTIVITIES}

\section{Ongoing Flask ${ }^{14} \mathrm{CO}_{2}$ Intercomparison}

John Miller (NOAA/ESRL) reported on the results from all 3 rounds of the ${ }^{14} \mathrm{CO}_{2}$ flask intercomparison, which was started in 2007 (Miller et al. 2011, 2013). This intercomparison is presently limited to AMS laboratories, which are capable of making measurements from relatively small volumes of whole air (i.e. yielding $\sim 40-100 \mu$ mole $\mathrm{CO}_{2}$ ). Contributors send between 2 and 4 air sampling flasks to the University of Colorado to be filled with whole air from 2 high-pressure gas cylinders: FARI-A and FARI-B. FARI-A is ambient air filled at Niwot Ridge, Colorado. FARI-B is ambient air

\footnotetext{
${ }^{1}$ GNS Science, Lower Hutt, New Zealand. Corresponding author. Email: j.turnbull@gns.cri.nz. ${ }^{2}$ CIRES, University of Colorado, Boulder, Colorado, USA.

${ }^{3}$ Scripps Institution of Oceanography, San Diego, California, USA.

${ }^{4}$ NOAA Earth System Research Laboratory, Boulder, Colorado, USA.

${ }^{5}$ INSTAAR, University of Colorado, Boulder, Colorado, USA.
} 


\section{$J$ Turnbull et al.}

that has been spiked with a small amount of ${ }^{14} \mathrm{C}$-free $\mathrm{CO}_{2}$ to obtain an air mixture with $\mathrm{CO}_{2}$ mole fraction enhanced by $\sim 40 \mu$ mole/mole and with a ${ }^{14} \mathrm{C}$ content $\left({ }^{14} \mathrm{C} / \mathrm{C}\right.$ ratio $)$ slightly below ambient.

The results show reasonable agreement between the participating laboratories but more spread than expected, and are reported in full in Miller et al. (these proceedings). Some of the spread between results from different laboratories may be related to choice of material used for standardization (Ox I vs. Ox II). This issue needs further investigation. Measurements of $\mathrm{CO}_{2}$ mole fraction and $\delta^{13} \mathrm{C}$ were made by some of the laboratories, and it appears that variability in filling of the flasks cannot explain the variability in $\Delta^{14} \mathrm{CO}_{2}$. However, measurement of $\mathrm{CO}_{2}$ mole fraction and $\delta^{13} \mathrm{C}$ may still help to understand the source of interlaboratory variability.

The workshop participants discussed the experimental design of the previous intercomparison and ideas for improvements for future rounds. The current flask filling method is to first "condition" the flasks by evacuating, then twice filling all flasks with the cylinder air and re-evacuating again, then filling flasks to slightly over ambient pressure with the cylinder air for distribution to the labs. This method was deemed to be adequate for the ${ }^{14} \mathrm{CO}_{2}$ intercomparison. The ${ }^{13} \mathrm{CO}_{2}$ intercomparison exercise uses a more rigorous flushing method whereby all flasks are connected in series and air from the cylinder is flushed through the "sausage" of flasks for a period of time before closing off all flasks for distribution to the labs (e.g. Mukai et al. 2005). This method may use too much air, and is unnecessary for the level of precision of the ${ }^{14} \mathrm{CO}_{2}$ intercomparison exercise. In particular, if flushing is done, a new tank is needed for every intercomparison, whereas the evacuation method currently in use allows the same tanks to be used for multiple intercomparison rounds. There remains sufficient air in these tanks for several more rounds at least.

Currently, additional control flasks are filled and measured at the University of Colorado and NOAA/ESRL for $\mathrm{CO}_{2}$ mole fraction and $\delta^{13} \mathrm{CO}_{2}$. It was agreed that all the future intercomparison flasks be measured for $\mathrm{CO}_{2}$ mole fraction and $\delta^{13} \mathrm{CO}_{2}$, and that the $\delta^{13} \mathrm{C}$ measurement be of sufficient quality to detect variability of $\sim 0.1 \%$ in $\delta^{13} \mathrm{C}$. It has not yet been agreed whether individual participants will make these measurements, or if they can be performed at the University of Colorado and NOAA/ESRL. A second intercomparison exercise, to be based on a distribution of pure $\mathrm{CO}_{2}$ produced from the same source, was proposed, so that differences arising from $\mathrm{CO}_{2}$ extraction procedures and graphitization/AMS measurements can be isolated. Two options for generating this $\mathrm{CO}_{2}$ were discussed: $\mathrm{CO}_{2}$ extracted at the University of Colorado from the existing FARI tanks; and obtaining modern $\mathrm{CO}_{2}$ from a source such as ethanol fermentation. Pure $\mathrm{CO}_{2}$ would be distributed in flame-sealed ampoules.

\section{AMS and Proportional Counting Intercomparison}

A major challenge is to compare atmospheric ${ }^{14} \mathrm{CO}_{2}$ results for a common source of air for both gas counting/liquid scintillation and AMS labs, as gas counting and liquid scintillation require much larger amounts of sample material than can be obtained from the $\sim 2$ - to 5-L flasks of air now used for AMS. Some intercomparison of this type has already been done on a limited basis. The University of Heidelberg has an ongoing in-house comparison whereby they collect $\mathrm{CO}_{2}$ absorbed onto $\mathrm{NaOH}$ for gas counting and simultaneously collect air from the same inlet line into polyethylenecoated aluminum bags. Aliquots from the bags are then measured by AMS (Vogel et al. 2011).

Ingeborg Levin and Samuel Hammer from the Heidelberg group volunteered to provide $\mathrm{CO}_{2}$ aliquots from the $\mathrm{NaOH}$ absorption for measurement in other AMS labs. Although this does not capture possible variability arising from interlaboratory differences in the extraction process, it will nevertheless provide for a comparison of the ${ }^{14} \mathrm{CO}_{2}$ measurement scale between labs. 


\section{Co-Located Sampling Intercomparisons}

Heather Graven (Scripps Institution of Oceanography) and Xiaomei Xu (University of California, Irvine) presented a comparison of results from 2 different flask sampling programs at Point Barrow, Alaska (Graven et al., these proceedings). They showed very good agreement between the 2 independent sampling and measurement programs, both using AMS measurement (Graven et al., these proceedings).

Co-located sampling was discussed as a further intercomparison exercise, but the participants felt that although this is desirable, it would be challenging to do this across all laboratories. Instead, it is recommended that this continue to be done when feasible as bilateral arrangements between labs rather than as a community exercise.

\section{Future Intercomparison Rounds}

The next round (round 4) of atmospheric ${ }^{14} \mathrm{CO}_{2}$ intercomparison is currently being planned. Future intercomparison rounds are expected to be approximately once every $1-2 \mathrm{yr}$, with the timing dependent on receiving flasks from the contributing laboratories and reporting of measurement results.

Round 4 will include 3 different intercomparison activities as discussed above. Participants are encouraged, but not required, to participate in all 3 intercomparisons:

A. Flasks of whole air for extraction, filled at University of Colorado. Only available to AMS labs. This is the same as the round $1-3$ intercomparisons, except that $\mathrm{CO}_{2}$ mole fraction and $\delta^{13} \mathrm{CO}_{2}$ measurements will be included.

B. Flame-sealed ampoules of $\mathrm{CO}_{2}$ from Heidelberg (Levin/Hammer), for direct comparison with the Heidelberg gas counting system. This could also include larger samples, enabling other liquid scintillation and gas counting labs to participate.

C. Flame-sealed ampoules of $\mathrm{CO}_{2}$ from University of Colorado (Lehman/Miller) from the same tanks as the whole air samples. Only available to AMS labs due to the limited size of tanks.

Any interested contributors who are not already involved should contact John Miller (john.b.miller@noaa.gov) for further information regarding participation. This intercomparison work does not have any direct funding, and the cost of preparation of samples is currently being carried by the University of Colorado and NOAA. Funding support, even at very small levels, would improve these intercomparisons, and any suggestions for funding avenues should be directed to John Miller.

\section{USE OF GAS STANDARD VS. SOLID STANDARDS FOR ATMOSPHERIC ${ }^{14} \mathrm{C}$ MEASUREMENTS}

The choice of standard material used in ${ }^{14} \mathrm{C}$ measurement was discussed. The preparation method for oxalic acid I and II is to combust and purify the solid material, which appears to introduce more variance than is seen in $\mathrm{CO}_{2}$ extracted from whole air (Graven et al. 2007; Graven 2008). This variance may be associated with small batch combustion of the solid materials. Preparation of large batches of $\mathrm{CO}_{2}$ from the solid materials may help with this, but there is also concern that a large batch may drift over time or have sudden shifts in ${ }^{14} \mathrm{C}$ value, and liquid $\mathrm{CO}_{2}$ (at pressure $>60$ bar) cannot be allowed to form in the storage container.

$\mathrm{CO}_{2}$ extracted from high-pressure cylinders of natural whole air has been used as a working reference for atmospheric measurements (Graven 2008). The mean value of $\mathrm{CO}_{2}$ in the whole air tank is characterized by normalizing it to Ox I over multiple AMS measurement runs. The gas standard is 


\section{$J$ Turnbull et al.}

then used to normalize authentic samples and "surveillance" gas standards in each individual wheel (Graven 2008).

Concerns about natural air standards are that they could potentially drift through time, and have the logistical challenge that cylinders will be used up fairly quickly. Participants agreed that moving completely away from the solid standards would be a mistake, and that the atmospheric ${ }^{14} \mathrm{C}$ community needs to remain tied to Ox I and/or Ox II, even if a reference gas material is also used as a working reference.

A small working group was formed to investigate the development of a gas standard for ${ }^{14} \mathrm{C}$, aiming to collaborate with other entities (such as the US National Institute of Standards and Technology) to help develop such a standard. Scott Lehman and Tom Guilderson will organize and lead this group. One major task of this working group will be to resolve the question of whether such a gas standard should be provided as whole air or as $\mathrm{CO}_{2}$.

\section{REPORTING OF UNCERTAINTIES IN ATMOSPHERIC ${ }^{14} \mathrm{C}$ MEASUREMENTS}

As atmospheric ${ }^{14} \mathrm{C}$ measurements are at the forefront of ${ }^{14} \mathrm{C}$ measurement precision, reporting of uncertainties has received considerable attention. At the sub-2\% level of precision now often reported for ${ }^{14} \mathrm{CO}_{2}$ measurements, the common practice in the ${ }^{14} \mathrm{C}$ community of reporting counting statistical uncertainties as the full uncertainty is unlikely to capture the entire measurement uncertainty (Miller et al., these proceedings). Therefore, it is recommended that reporting of atmospheric ${ }^{14} \mathrm{C}$ results should include uncertainties that consider long-term repeatability of authentic atmospheric materials. Repeatability is typically determined as the scatter of long-term repeated measurements of authentic atmospheric materials such as extraction aliquots from surveillance cylinders of whole air or replicates of atmospheric samples.

\section{INTERCOMPARISON ACTIVITIES FOR ${ }^{14} \mathrm{C}$ IN OTHER ATMOSPHERIC TRACE GASES}

There is some interest in developing intercomparisons for ${ }^{14} \mathrm{CH}_{4}$ and ${ }^{14} \mathrm{CO}$, as several laboratories are now making one or both of these measurements. A major difficulty is that large amounts of air are needed for measurement. The consensus was that bilateral intercomparisons should be encouraged, and that the need for a formal intercomparison will be re-evaluated at the next WMO GGMT meeting.

\section{REFERENCES}

Graven HD. 2008. Advancing the use of radiocarbon in studies of global and regional carbon cycling with high precision measurements of ${ }^{14} \mathrm{C}$ in $\mathrm{CO}_{2}$ from the Scripps $\mathrm{CO}_{2}$ Program [PhD thesis]. La Jolla: Scripps Institute of Oceanography, University of California, San Diego.

Graven HD, Guilderson TP, Keeling RF. 2007. Methods for high-precision ${ }^{14} \mathrm{C}$ AMS measurement of atmospheric $\mathrm{CO}_{2}$ at LLNL. Radiocarbon 49(2):349-56.

Graven HD, Xu X, Guilderson TP, Keeling RF, Trumbore SE, Tyler S. 2013. Comparison of independent $\Delta^{14} \mathrm{CO}_{2}$ records at Point Barrow, Alaska. Radiocarbon, these proceedings, doi:10.2458/azu_js_rc.55.16220.

Miller J, Wolak C, Lehman S, Allison C, Graven H, Guilderson T, Keeling R, Meijer H, Nakamura T, Nakazawa T, Neubert R, Smith A, Southon J, Xu X. 2011.
Preliminary results from the first inter-comparison of accelerator mass spectrometry atmospheric ${ }^{14} \mathrm{CO}_{2}$ measurements. In: Brand W, editor. Report of the 15th WMO/IAEA Meeting of $\mathrm{CO}_{2}$ Experts on Carbon Dioxide, Other Greenhouse Gases and Related Tracers Measurements Techniques, Jena, Germany, 7-10 September 2009. TD No. 1553. Geneva: World Meteorological Organization Atmospheric Watch. p 216-8.

Miller J, Lehman S, Wolak C, Turnbull J, Dunn G, Graven H, Keeling R, Meijer HAJ, AT Aerts-Bijma, Palstra SWL, Smith AM, Allison C, Southon J, Xu X, Nakazawa T, Aoki S, Nakamura T, Guilderson T, LaFranchi B, Mukai H, Terao Y, Uchida M, Kondo M. 2013. Initial results of an intercomparison of AMS-based atmospheric ${ }^{14} \mathrm{CO}_{2}$ measurements. Radiocarbon, these proceedings, doi:10.2458/azu_js_rc.55.16382. 


\section{Atmospheric Radiocarbon Workshop Report}

Mukai H, Nakazawa T, Brand WA, Huang L, Levin I, Allison CE, Leuenberger M, Assonov S. 2005. About disagreements in inter-comparison activities of isotope ratio measurements for $\mathrm{CO}_{2}$. In: Miller J, Conway T, editors. Proceedings of the 13th IAEA/WMO Meeting of $\mathrm{CO}_{2}$ Experts, Boulder, September 2005. p 41-8.

Vogel F, Jeschka J, Kromer B, Steinhof A, Hammer S, Levin I. 2011. A robust setup for long-term monitoring of fossil fuel $\mathrm{CO}_{2}$ and other trace gases, and its test against established conventional monitoring in Heidelberg. In: Brand W, editor. Report of the 15th WMO/IAEA Meeting of $\mathrm{CO}_{2}$ Experts on Carbon Diox- ide, Other Greenhouse Gases and Related Tracers Measurements Techniques, Jena, Germany, 7-10 September 2009. TD No. 1553. Geneva: World Meteorological Organization Atmospheric Watch.

World Meteorological Organization [WMO]. 2011. Expert group recommendations. In: Brand W, editor. Report of the 15th WMO/IAEA Meeting of $\mathrm{CO}_{2}$ Experts on Carbon Dioxide, Other Greenhouse Gases and Related Tracers Measurements Techniques, Jena, Germany, 7-10 September 2009. TD No. 1553. Geneva: World Meteorological Organization Atmospheric Watch. p 1-37. 